\title{
THE ANTIBIOTIC YA-56 COMPLEX : ISOLATION, PURIFICATION AND PHYSICOCHEMICAL PROPERTIES OF THE MAIN COMPONENTS
}

\author{
Yukio Ito, Yoshrtami Ohashi, Shuzo Kawabe, \\ Masaharu Sakurazawa, Toshio Ogawa, \\ Yoshiyuki Egawa and Tomoharu OKuda \\ Microbial Chemistry Research Laboratory, \\ Tanabe Seiyaku Co., L.td., Toda, Saitama, Japan \\ (Received for publication October 26, 1972)
}

\begin{abstract}
Isolation, purification and physicochemical properties of the antibiotic complex YA-56, a family of phleomycin-bleomycin group, are described. The antibiotic YA-56 complex was found to be composed mainly of two active components named YA-56 X and $\mathrm{Y}$. These components were clearly differentiated from the reported phleomycins and bleomycins by their physicochemical properties. However, by direct comparison, YA-56 X was found to be identical with zorbamycin reported recently. YA-56 Y was recognized to be a new antibiotic.
\end{abstract}

In the course of the screening of new antibiotics, an antibiotic complex named YA-56 belonging to the phleomycin-bleomycin group antibiotics was isolated from the culture filtrate of a streptomyces. The taxonomic studies and the antibiotic production by the YA-56 producing strain, Streptomyces humidus var. antitumoris, were reported in the preceeding paper ${ }^{1)}$.

Antibiotic YA-56 was mainly composed of two active components named YA-56 $\mathrm{X}$ and $\mathrm{Y}$, of which isolation and characterization have already been communicated briefly $y^{2)}$. The present paper deals with the experimental details of the isolation, purification and physicochemical properties of YA-56 X and $\mathrm{Y}$.

Examination of chemical constituents of YA-56 X and $Y$ achieved through their degradation products will be dealt with in the succeeding paper ${ }^{3)}$. Details of the biological properties of $\mathrm{YA}-56 \mathrm{X}$ and $\mathrm{Y}$ will be reported later.

\section{Preparation of $\mathrm{YA}-56 \mathrm{X}$ and $\mathrm{Y}$}

YA-56 was recovered from the filtered broth by the procedure outlined in Chart 1. The active principle in the filtrate was first isolated as a bluish powder by an adsorption procedure on a high porous polymer (Duolite S-30) followed by alumina chromatography. By paper chromatography (Fig. $3 \mathrm{a}$ and $3 \mathrm{~b}$ ), the bluish powder thus obtained was found to be mainly composed of two active components named $\mathrm{X}$ and $Y$. Separation of $X$ and $Y$ components was effectively achieved by gel filtration on acid pre-treated Sephadex G-154). After separation, YA-56 X and Y were respectively purified by Sephadex LH-20 gel filtration and chromatographically homogenous bluish powders were obtained. The bluish powders which contained cupric ion as a 
chelating metal were then treated with hydrogen sulfide. Thus, being freed from cupric ion, each component was obtained as a white amorphous powder.

\section{Physicochemical \\ Properties of $\mathrm{YA}-56 \mathrm{X}$ and $\mathrm{Y}$}

Some of physicochemical properties (m.p., analytical data, UV maxima, ORD data and Rf values) of $\mathrm{YA}-56 \mathrm{X}$ and $\mathrm{Y}$ are summarized in Table 1, together with those of their $\mathrm{Cu}$-complexes. Judging from the elemental analysis data, YA-56 X and its Cu-complex must be present as their hydrochlorides.

The infrared spectra of YA-56 X and Y (Fig. 1 a) were quite similar to each other and indicated the presence of $\mathrm{OH} /$ $\mathrm{NH}$ at 3400 3200, carbonyl at $1700 \sim 1690$ (shoulder) and amide carbonyl at 1645 1640 (amide I) and $1545 \mathrm{~cm}^{-1}$ (amide II). YA-56 $\mathrm{X}$ and $\mathrm{Y} \mathrm{Cu}$-complexes showed similar infrared spectra (Fig. $1 \mathrm{~b})$ to those of $\mathrm{YA}-56 \mathrm{X}$ and $\mathrm{Y}$.
Chart 1. Preparation of YA-56 X and Y. Filtered broth (pH 6.8)

$$
\begin{aligned}
& \text { adsorbed on Duolite } \mathrm{S}-30 \text { resin } \\
& \text { and eluted with } 0.1 \mathrm{~N} \mathrm{HCl-acetone} \\
& \text { mixture }(2: 8)
\end{aligned}
$$

Active eluate (pH 6.8)

Crude powder
$\mid \begin{aligned} & \text { extracted with MeOH, concentrated } \\ & \text { and pptd. with acetone }\end{aligned}$

Purified powder

$\mid \begin{aligned} & \mathrm{Al}_{2} \mathrm{O}_{3} \text { chromatography and eluted } \\ & \text { with } \mathrm{H}_{2} \mathrm{O}\end{aligned}$
Active fraction
Bluish powder
\[ \begin{array}{l}\text { lyophilized } \\ \text { and filtration on Sephadex } \mathrm{LH}-20\end{array} \]
active fraction

Active fraction evaporated in vacuo and pptd. with acetone

Purified powder

$\mid \begin{aligned} & \text { gel fitration on acid pre-treated } \\ & \text { Sephadex } G-15 \text { and eluted with } 0.2 \mathrm{M} \\ & \mathrm{NaCl} \text { solution }\end{aligned}$

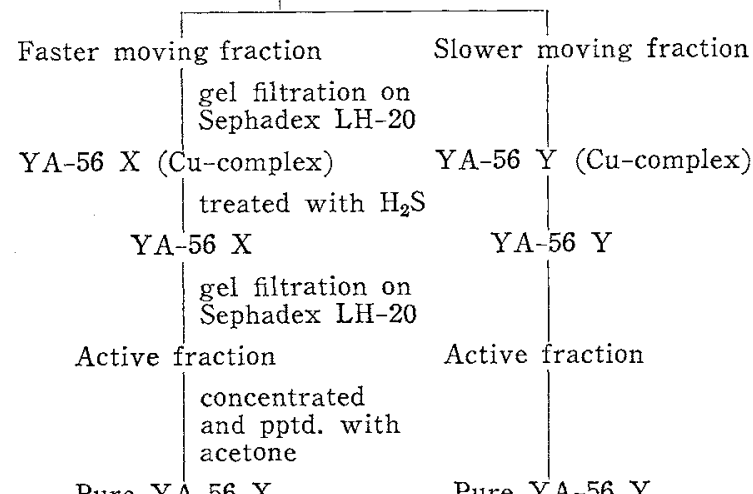

Pure YA-56 X

The UV spectra of YA-56 X, Y and their Cu-complexes are shown in Fig. $2 \mathrm{a}$ and $2 \mathrm{~b}$.

YA-56 X and Y were positive to MoLISE and anthrone tests, indicating the presence of carbohydrate constituent(s) in the molecule. DRAGENDORFF, EHRLICH and PAULy color reactions were positive, while the ninhydrin, Elson-Morgan, SAKaguchi and biuret reactions were negative.

YA-56 $\mathrm{X}$ and $\mathrm{Y}$, as well as their Cu-complexes, were soluble in water, methanol, dimethylformamide and dimethylsulfoxide, slightly soluble in ethanol and insoluble in propanol, butanol, acetone, ethyl acetate, chloroform, benzene, ether, petroleum ether and dioxane.

\section{Comparison of YA-56 with Phleomycin, Bleomycin and Zorbamycin}

From the above-described physicochemical properties (IR, UV, color reactions and the chelating property) and the biological properties, YA-56 X and Y seemed to be 
Table 1. Physicochemical properties of $\mathrm{YA}-56 \mathrm{X}$ and $\mathrm{Y}$.

\begin{tabular}{|c|c|c|c|c|c|}
\hline & & \multicolumn{2}{|c|}{ YA-56 X } & \multicolumn{2}{|c|}{$\mathrm{YA}-56 \mathrm{Y}$} \\
\hline & & $\begin{array}{c}\mathrm{YA}-56 \mathrm{X} \\
\text { Hydrochloride } \\
(\mathrm{Cu} \text {-complex })\end{array}$ & $\begin{array}{c}\text { YA-56 X } \\
\text { Hydrochloride }\end{array}$ & $\begin{array}{c}\mathrm{YA}-56 \mathrm{Y} \\
(\mathrm{Cu}-\mathrm{complex})\end{array}$ & $\begin{array}{c}\mathrm{YA}-56 \mathrm{Y} \\
\end{array}$ \\
\hline \multicolumn{2}{|c|}{ Melting point } & $195 \sim 200^{\circ} \mathrm{C}$ (dec.) & $198 \sim 202^{\circ} \mathrm{C}$ (dec.) & $190 \sim 197^{\circ} \mathrm{C}$ (dec.) & $188 \sim 197^{\circ} \mathrm{C}$ (dec.) \\
\hline \multicolumn{2}{|c|}{$\begin{array}{l}\text { Elementary } \\
\text { analysis*a) } \\
(\%)\end{array}$} & $\begin{array}{cr}\mathrm{C} & 43.24 \\
\mathrm{H} & 4.65 \\
\mathrm{~N} & 17.28 \\
\mathrm{~S} & 4.70 \\
\mathrm{Cl} & 4.86 \\
\mathrm{Cu} & 4.34\end{array}$ & $\begin{array}{cr}\mathrm{C} & 45.41 \\
\mathrm{H} & 5.82 \\
\mathrm{~N} & 17.60 \\
\mathrm{~S} & 4.64 \\
\mathrm{Cl} & 4.69\end{array}$ & $\begin{array}{lr}\mathrm{C} & 42.22 \\
\mathrm{H} & 5.51 \\
\mathrm{~N} & 14.64 \\
\mathrm{~S} & 3.56 \\
\mathrm{C} 1 & - \\
\mathrm{Cu} & 2.74\end{array}$ & $\begin{array}{lr}\mathrm{C} & 42.85 \\
\mathrm{H} & 5.55 \\
\mathrm{~N} & 14.64 \\
\mathrm{~S} & 3.57 \\
\mathrm{Cl} & -\end{array}$ \\
\hline $\begin{array}{l}\text { Molec } \\
\text { weigh }\end{array}$ & $\begin{array}{l}\text { ular } \\
\text { titb) }\end{array}$ & 641 & 559 & \multicolumn{2}{|c|}{ not measured } \\
\hline $\begin{aligned} & \mathrm{UV}: \lambda_{\mathrm{ma}}^{\mathrm{H}_{2} \mathrm{C}} \\
&\left(\mathrm{E}_{1 \mathrm{c}}^{\mathrm{1} \%}\right. \\
&\end{aligned}$ & $\begin{array}{l}0 \\
\text { axm, } \\
(m) \\
m\end{array}$ & $\begin{array}{cc}246.5 & (126.6) \\
\& 300 \sim 303 & (45.6)\end{array}$ & $\begin{array}{rr}234 & (155.9) \\
\& 295 & (36.9)\end{array}$ & $\begin{array}{rr}245.5 & (134.0) \\
\& 302.0 & (47.0)\end{array}$ & $\begin{array}{r}240 \sim 241(117.5) \\
\& 297(36.4)\end{array}$ \\
\hline \multicolumn{2}{|c|}{$\mathrm{ORD}\left(\mathrm{H}_{2} \mathrm{O}\right)$} & $\begin{array}{l}\text { positive cotton curve } \\
{[\alpha]_{620}+217.6 \text { (peak) }} \\
{[\alpha]_{589}+151.5 \text { (D-line) }} \\
{[\alpha]_{560} \quad 0.0} \\
{[\alpha]_{516}-109.6 \text { (trough) }} \\
(c 0.363)\end{array}$ & $\begin{array}{l}\text { positive cotton curve } \\
{[\alpha]_{589}+20 \text { (D-line) }} \\
{[\alpha]_{330}+90 \text { (peak) }} \\
{[\alpha]_{296} 0.0} \\
{[\alpha]_{272}-360 \text { (trough) }} \\
(c 0.05)\end{array}$ & $\begin{array}{l}\text { positive cotton curve } \\
{[\alpha]_{615}+187.5 \text { (peak) }} \\
{[\alpha]_{589}+134.8 \text { (D-line) }} \\
{[\alpha]_{559.5} 0.0} \\
{[\alpha]_{510}-85.4 \text { (trough) }} \\
(c 0.328)\end{array}$ & not measured \\
\hline $\mathrm{Rf} * c)$ & $\begin{array}{l}\text { I } \\
\text { II } \\
\text { III } \\
\text { IV } \\
\text { V } \\
\text { VI } \\
\text { VII }\end{array}$ & $\begin{array}{l}0.00 \\
0.05 \\
0.93 \\
0.10 \\
0.47 \\
0.30 \\
0.23\end{array}$ & $\begin{array}{l}0.00 \\
0.05 \\
0.93 \\
0.10 \\
0.47 \\
0.30 \\
0.23\end{array}$ & $\begin{array}{l}0.00 \\
0.05 \\
0.93 \\
0.10 \\
0.47 \\
0.45 \\
0.31\end{array}$ & $\begin{array}{l}0.00 \\
0.05 \\
0.93 \\
0.10 \\
0.47 \\
0.45 \\
0.31\end{array}$ \\
\hline
\end{tabular}

*a) Because of hygroscopicity, analytical values of YA-56 X varied on each sample in accordance with the moisture contained. To avoid such fluctuation, the water content was determined simultaneously by a thermogravimetric-Differential Scanning Calorimeter (Rigaku Denki Kogyo Co. Standard type) on each thample and the analytical values were corrected based on the moisture content. For this reason, analytical values of $\mathrm{YA}-56 \mathrm{X}$ and its Cu-complex were revised as shown. Presentation of the empirical formula is reserved until the survey of the constituents of YA-56 has been completed.

*b) Molecular weicht was determined by vapor pressure osmometry in $\mathrm{MeOH}$.

*) PPC : Toyo No $51 \mathrm{~A}$ paper, ascending. Bioatiography with Bacillus subtilis PCI 219 . Solvent system : I : water-saturated $n$-BuOH, II : acetone $-\mathrm{H}_{2} \mathrm{O}(1: 1)$, III : phenol- $\mathrm{H}_{2} \mathrm{O}(3: 1)$, IV $: n-\mathrm{BuOH}-\mathrm{MeOH}-\mathrm{H}_{2} \mathrm{O}(4: 1: 2)$, $\mathrm{V}: n$-BuOH $-\mathrm{MeOH}-\mathrm{H}_{2} \mathrm{O}$-methyl orange $(40 \mathrm{ml}: 10 \mathrm{ml}: 20 \mathrm{ml}: 1.5 \mathrm{~g})$, VI: $n-\mathrm{BuOH}-\mathrm{pyridine}-\mathrm{AcOH}-\mathrm{H}_{2} \mathrm{O}(15:$ $10: 3: 12)$, VII $: n-\mathrm{BuOH}-\mathrm{ACOH}-\mathrm{H}_{2} \mathrm{O}(4: 1: 5)$.

related to the previously reported phleomycins ${ }^{5)}$ and bleomycins ${ }^{6)}$.

According to UMEZAWA et al. ${ }^{6)}$ the ratio of UV absorbancies at the two absorption maxima, 244 246 and 295 297 nm, of phleomycin and bleomycin Cu-complexes is of great use in differentiating the members of this family. The ratio reported is $1.1 \sim 1.3$ in bleomycins, about $2.7 \sim 2.8$ in phleomycin $D_{1}, E, G, H$ and $\mathrm{I}$, and about 1.1 1.3 in phleomycin $\mathrm{C}, \mathrm{D}_{2}$ and $\mathrm{F}$. With regard to UV spectra, YA-56 resembles phleomycin $\mathrm{D}_{1}, \mathrm{E}, \mathrm{G}, \mathrm{H}$ and $\mathrm{I}$, since the ratio is 2.78 in $\mathrm{X}$ and 2.8 in $\mathrm{Y}$.

To compare YA-56 with the phleomycin complexes, chromatographic elution patterns on CM-Sephadex column were examined according to IKEKAWA et $a l^{5)}$. As illustrated in the preliminary communication ${ }^{2)}, \mathrm{YA}-56 \mathrm{X}$ and $\mathrm{Y}$ were eluted with 0.2 $M$ ammonium formate buffer, similarly to phleomycin $D_{1}$. Therefore, YA-56 was directly compared with the phleomycin $D_{1}$ fraction isolated from phleomycin complex by the above-described chromatographic procedure. As shown in Fig. $3 \mathrm{a}$ and $3 \mathrm{~b}$, YA-56 X and Y were clearly differentiated from phleomycin $D_{1}$. Thus, the difference 
Fig. 1 a. Infrared spectra of $\mathrm{YA}-56 \mathrm{X}$ and $\mathrm{Y}$ in nujol.

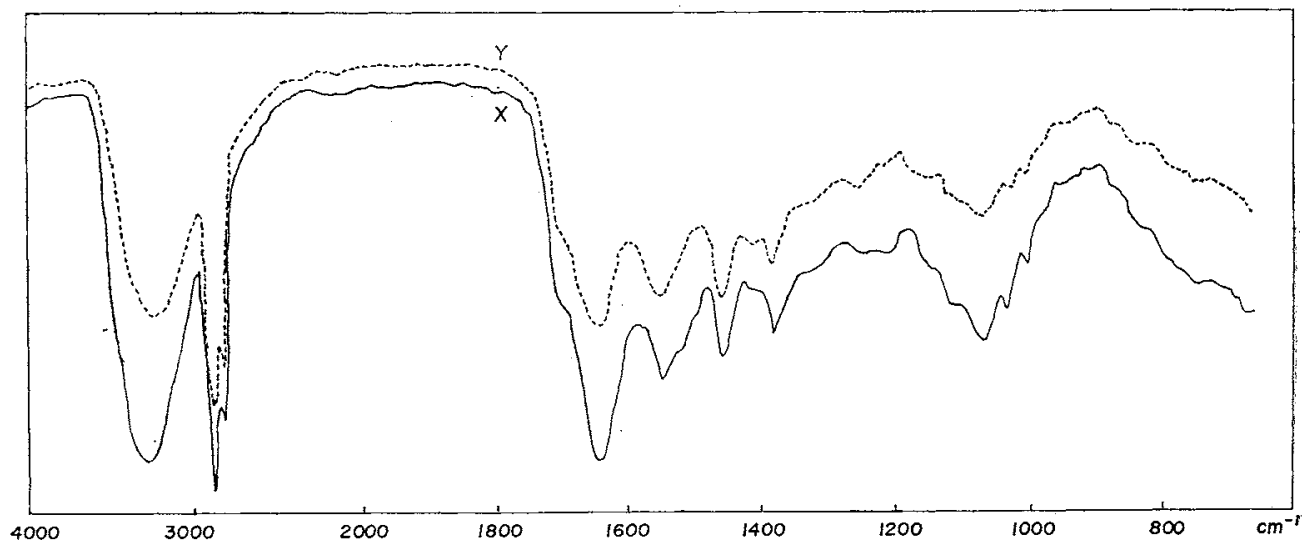

Fig. 1 b. Infrared spectra of $\mathrm{YA}-56 \mathrm{X}$ and $\mathrm{Y}$ (Cu-complex) in nujol.

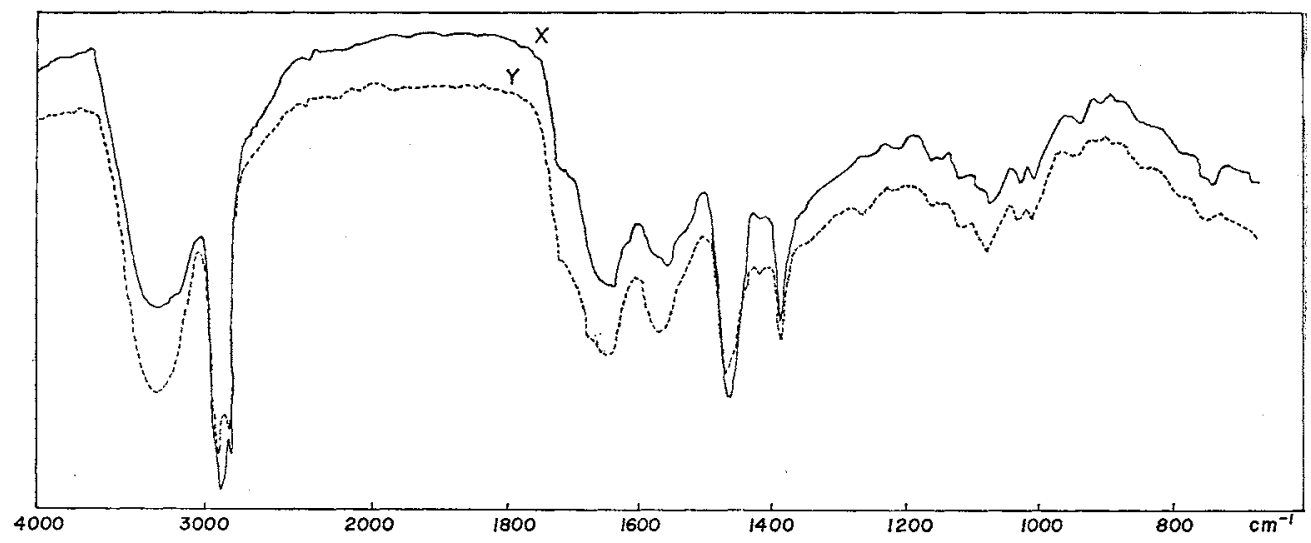

of YA-56 X and Y from each components of phleomycin and bleomycin was established. This conclusion has been strongly supported by the comparisons of the constituents of these antibiotics, which will be mentioned in the succeeding paper ${ }^{3}$.

Recently ARGOUDELIS et al. ${ }^{7)}$ reported on production, isolation and characterization of zorbamycin, zorbonomycin B and zorbonomycin C, which were likely new members. of phleomycin-bleomycin group antibiotics. Among these antibiotics, zorbamycin, which gave the UV absorption curve and the CM Sephadex elution pattern of phleomycin $D_{1}$ type seemed to be similar to YA-56 X. Thus, YA-56 X and Y were compared directly with the authentic sample of zorbamycin, which was kindly afforded by Dr. ARgoudelis. As shown in Fig. $3 \mathrm{a}$ and $3 \mathrm{~b}$, the chromatographic behaviors of $\mathrm{YA}-56 \mathrm{X}$ and zorbamycin were the same. Moreover, YA-56 X and zorbamycin were not separable by CM Sephadex C-25 column chromatography. The NMR spectrum of zorbamycin which was published in the paper ${ }^{7)}$ appeared to be identical with that of YA-56 X. As a result, zorbamycin and YA-56 X are thought to be identical. Comparative study of the hydrolysates of $\mathrm{YA}-56 \mathrm{X}$ and zorbamycin, which will be mentioned in the succeeding paper ${ }^{3)}$, supports their identity. YA-56 $\mathrm{Y}$ is readily 
Fig. 2a. Ultraviolet absorption spectra of $\mathrm{YA}-56 \mathrm{X}$ (in $\mathrm{H}_{2} \mathrm{O}$ ).

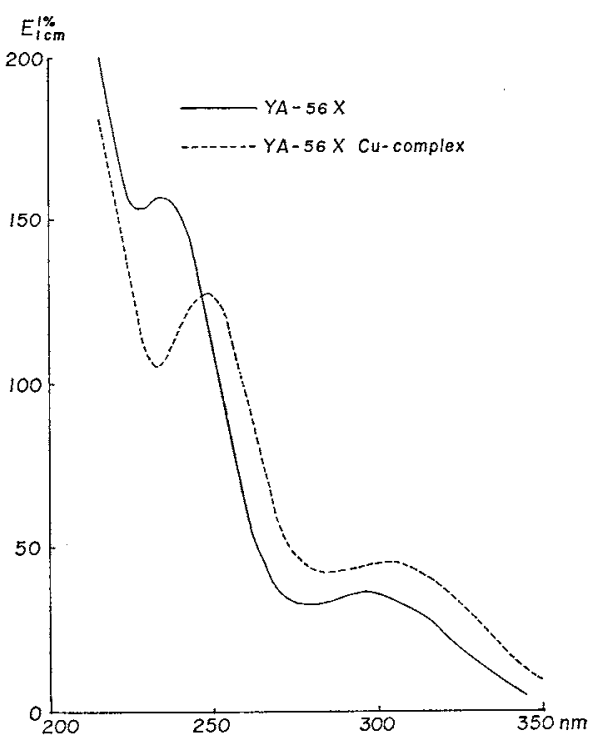

Fig. 3a. Paper chromatographic comparison of YA-56 with related antibiotics.

Paper: Toyo No. $51 \mathrm{~A}$ (descending)

Solvent : $n-\mathrm{BuOH}$-pyridine-AcOH- $\mathrm{H}_{2} \mathrm{O}$ $(15: 10: 3: 12)$

Bioautography: Bacillus subtilis PCI 219 ,

Klebsiella pneumoniae PCI 602.

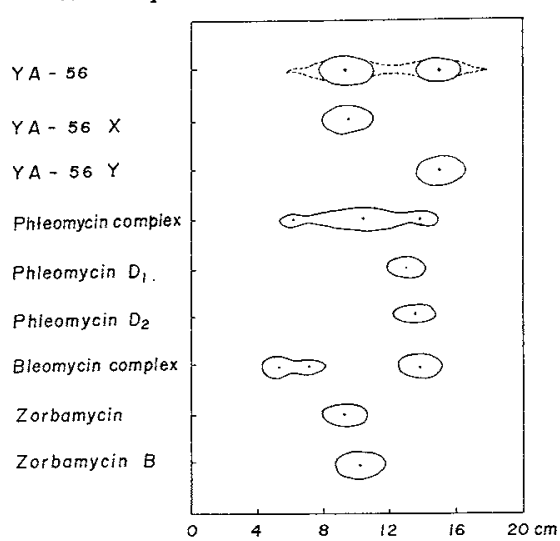

Fig. 2 b. U1traviolet absorption spectra of YA-56 $\mathrm{Y}$ (in $\mathrm{H}_{2} \mathrm{O}$ ).

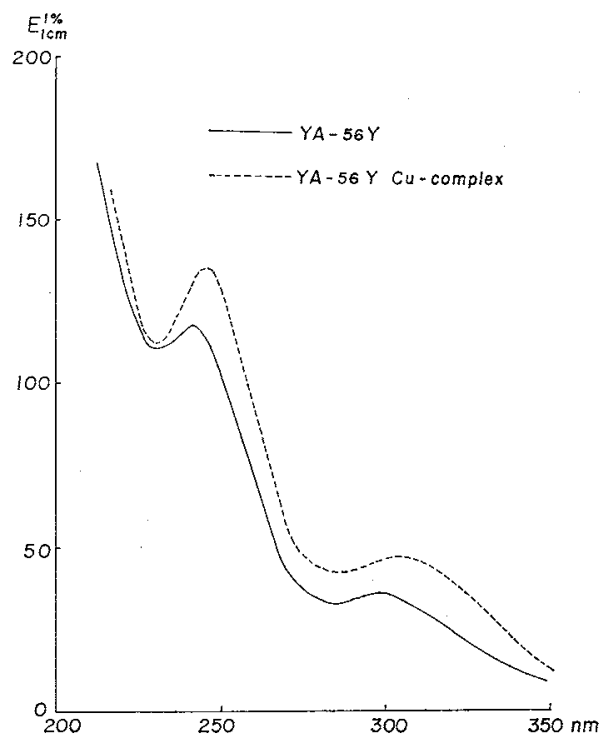

Fig. 3 b. Thin-layer chromatographic comparison of YA-56 with related antibiotics. Plate: Cellulose (E. Merck)

Solvent: $0.1 \mathrm{M} \mathrm{NH} \mathrm{N}_{4} \mathrm{Cl}(\mathrm{pH}$ 7.5)

Bioautography : Bacillus subtilis PCI 219 Klebsiella pneumoniae PCI 602.

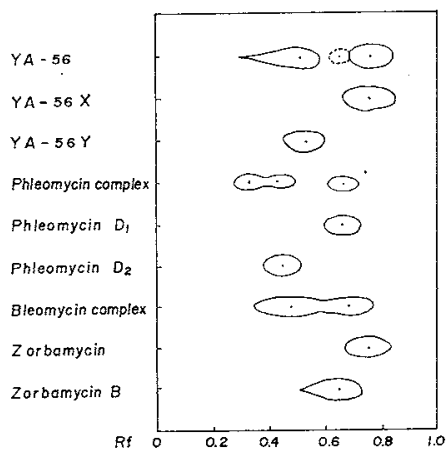

distinguished from zorbonomycins $B$ and $C$ by their UV spectra and elution patterns of CM Sephadex.

It was quite surprising that zorbamycin (patent name: zorbonomycin) and YA-56 $\mathrm{X}$ were independently found and characterized almost at the same time ${ }^{8,9}$.

\section{Experimental}

\section{Isolation and Purification}

In the course of purification, a cylinder-cup or pulp-disc assay method was applied using Bacillus subtilis PCI 219 and Escherichia coli NIHJ as test organisms. Column chromatographic fractions and the isolated products in all stages of the purification were also monitored by ascending paper chromatography on Toyo No. $51 \mathrm{~A}$ paper using solvent 
system $\mathrm{A}\left(\mathrm{BuOH}-\right.$ pyridine $\left.-\mathrm{AcOH}-\mathrm{H}_{2} \mathrm{O}, 15: 10: 3: 12\right)$ and/or solvent system $\mathrm{B}(0.05 \mathrm{M}$ $\mathrm{NH}_{4} \mathrm{Cl}, \mathrm{pH}$ 7.5) for development, and using B. subtilis PCI 219 and/or Klebsiella pneumoniae PCI 602 as the test organisms for bioautography. All solvent removals were carried out in vacuo under $40^{\circ} \mathrm{C}$.

The fermentation broth was filtered with Celite 545 and adjusted to $\mathrm{pH} 6.8$. The filtered broth (1,300 liters) was poured onto a column of Duolite S-30 (20 liters, Diamond Shamrock Chemical Co.) charged in a QVF glass tube $(28 \times 200 \mathrm{~cm})$. After adsorption, the column was washed with water (200 liters) and $80 \%$ aqueous acetone (50 liters), and then the column was eluted with $0.1 \mathrm{~N}$ hydrochloric acid-acetone mixture (2:8) (100 liters). The active eluate was adjusted to $\mathrm{pH} \quad 6.5 \sim 6.8$ and concentrated. The concentrate was lyophilized to give a brown colored powder $(210 \mathrm{~g})$. The powder was extracted with $\mathrm{MeOH}$ ( 0.5 liter $\times 3)$, and the extract was concentrated to 0.8 liter, to which was added acetone (9 liters) to precipitate a brownish powder $(55 \mathrm{~g})$. This powder was dissolved in $\mathrm{H}_{2} \mathrm{O}$ (100 $\mathrm{ml}$ ) and poured onto a column $(8 \times 200 \mathrm{~cm})$ of alumina $(7.5 \mathrm{~kg})$. The column was developed with water and the eluate was fractionated into three portions: the first fraction (Fr. I, $250 \mathrm{ml}$ ), the second fraction (Fr. II, 1,320 ml) and the third fraction (Fr. III, 10,730 ml). Fraction II, which was bluish in color and contained main active components, was adjusted to $\mathrm{pH} 6.4 \sim 6.8$ and lyophilized to yield a bluish green powder. The powder was extracted with $\mathrm{MeOH}(125 \mathrm{ml})$ and the extract was concentrated to $50 \mathrm{ml}$. Then, the solution was applied onto a column $(5 \times 135 \mathrm{~cm})$ of Sephadex LH-20. By developing the column with $\mathrm{MeOH}$, the following three fractions were obtained; the first fraction (Fr. IV, $550 \mathrm{ml}$ ), the second fraction (Fr. V, $250 \mathrm{ml}$ ) and the third fraction (Fr. VI, 1,670 ml). The main active fraction (Fr. V) was concentrated to $95 \mathrm{ml}$. Acetone was added to this concentrate to yield a blue powder $(1.5 \mathrm{~g})$. This powder was repeatedly ( $2 \sim 3$ times) purified by gel filtration on Sephadex $\mathrm{LH}-20$ using $\mathrm{MeOH}$ as a solvent in the manner described above. Purified hydrochloride of YA-56 Cu-complex $(500 \mathrm{mg})$ was obtained as a blue powder. The side fractions, Fr. I, III, IV and VI were combined and the pool was subjected to column chromatography on a column of alumina, Sephadex G-15 and Sephadex LH-20, successively. By treating the eluate thus obtained in the same manner as described above, additional hydrochloride of YA-56 Cu-complex $(379 \mathrm{mg})$ was recovered. Total yield was $12.3 \%$

\section{Separation of $\mathrm{YA}-56 \mathrm{X}$ and $\mathrm{Y}$}

Sephadex G-15 (2.4 liters) was boiled in $1 \mathrm{~N} \mathrm{HCl}$ (2 liters) for 2 hours. After cooling, the Sephadex was washed with water until the washed solution showed $\mathrm{pH}$ of about 6.2. Then, the Sephadex gel was charged in a column $(5 \times 135 \mathrm{~cm})$. The hydrochloride of YA$56 \mathrm{Cu}$-complex $(1.78 \mathrm{~g})$ was dissolved in $0.2 \mathrm{M}$ aqueous $\mathrm{NaCl}$ solution and the solution was poured onto the column. By developing the column with the same solvent, YA-56 was observed to be separated into two blue colored bands along the column. Two main eluates were collected by continuous development with $0.2 \mathrm{M}$ aqueous $\mathrm{NaCl}$. The faster moving eluates containing the $\mathrm{X}$ component were combined and the solution (245 $\mathrm{ml})$ was lyophilized to give a blue powder $(1.12 \mathrm{~g})$. The slower moving eluates containing the $\mathrm{Y}$ component were pooled and the solution $(1,400 \mathrm{ml})$ was lyophilized to yield a blue powder $(5.5 \mathrm{~g})$. The powder containing the $\mathrm{X}$ component was dissolved in $\mathrm{MeOH}-\mathrm{H}_{2} \mathrm{O}(5: 1,18 \mathrm{ml})$ and the solution was poured onto a column of Sephadex LH-20 (2.4 liters). By developing the column with $\mathrm{MeOH}$, the blue colored fractions which showed antimicrobial activity were collected and the solution was concentrated to $20 \mathrm{ml}$. Acetone $(200 \mathrm{ml})$ was added to the concentrate to yield a precipitate. The precipitate was again dissolved in $\mathrm{MeOH}(5 \mathrm{ml})$ and the solution was subjected to gel filtration on a column of Sephadex $\mathrm{LH}-20$, using $\mathrm{MeOH}$ as a solvent and the fractions showing $\mathrm{Rf}$ values of 0.3 on a paper chromatography (solvent system A) were combined. Concentration of the eluate followed by precipitation with acetone afforded the pure sample of the hydrochloride of $\mathrm{YA}-56 \mathrm{X} \mathrm{Cu}$-complex as a blue powder $(167 \mathrm{mg})$. For the separation of the YA-56 Y, the blue powder containing 
the $\mathrm{Y}$ component $(5.5 \mathrm{~g})$ was dissolved in $\mathrm{MeOH}-\mathrm{H}_{2} \mathrm{O}(5: 1,30 \mathrm{ml})$ and the solution was poured onto a column $(5 \times 135 \mathrm{~cm})$ of Sephadex LH-20. By developing the column with $\mathrm{MeOH}$, the blue colored fractions $(300 \mathrm{ml})$ showing antimicrobial activity were collected. The pool was concentrated to $30 \mathrm{ml}$. Addition of acetone $(200 \mathrm{ml})$ to the solution gave a precipitate $(400 \mathrm{mg}$ ), which was further purified by gel filtration of Sephadex LH-20 column in the same manner as described above to yield a purified sample of YA-56 Y Cu-complex (78 $\mathrm{mg})$.

\section{Preparation of $\mathrm{YA}-56 \mathrm{X}$ and $\mathrm{Y}$}

The hydrochloride of YA-56 X Cu-complex ( $160 \mathrm{mg}$ ) was dissolved in dehydrated $\mathrm{MeOH}$ $(16 \mathrm{ml})$ and dry hydrogen sulfide gas was introduced into the solution at room temperature. The precipitated copper sulfide was removed by centrifugation. The pale yellow supernatant was evaporated. The residue $(120 \mathrm{mg}$ ) was dissolved in $\mathrm{MeOH}(1.5 \mathrm{ml})$ and the solution was applied on a column $(1.8 \times 90 \mathrm{~cm})$ of Sephadex $\mathrm{LH}-20$. By using $\mathrm{MeOH}$ as the developing solvent, main peak fractions showing antimicrobial activity were collected and combined. The combined solution was concentrated and precipitated with acetone to give a pure sample of the hydrochloride of YA-56 X (97.5 mg) as a white amorphous powder.

The methanolic solution of YA-56 Y Cu-complex $(60 \mathrm{mg} / \mathrm{ml})$ was treated with hydrogen sulfide in the manner described for YA-56 X. After purification by Sephadex LH-20 gel filtration, the pure sample of YA-56 Y $(35 \mathrm{mg})$ was obtained as a white amorphous powder.

\section{Acknowledgement}

We are indebted to Drs. H. Umezawa, K. Maeda, T. Takita and S. Kondo, Institute of Microbial Chemistry, for their generous supply of authentic samples of bleomycin and phleomycin Cu-complexes, and the valuable information and advice. We are also grateful to Dr. A. D. Argoudelis, The Upjohn Company, for his kind supply of zorbamycin and zorbonomycin B. Thanks are expressed to Dr. K. Kotera and his collaborators of the Analytical Center of this Company for the instrumental and elementary analyses and to Mr. H. YoshIDA of this laboratory for his technical assistance.

\section{References}

1) Furumat, T.; K. Takeda, K. Tani, N. Matsuzawa, Y. Shrmizu, Y. Ohashi \& T. Okuda: The antibiotic YA-56 complex: Taxonomy and production of the producing strain. J. Antibiotics $26: 70 \sim 76,1973$

2) Ito, Y.; Y. Ohashi, Y. Egawa, T. Yamaguchi, T. Furumai, K. Enomoto \& T. Oxuda: Antibiotic YA-56, a new family of phleomycin-bleomycin group antibiotics. J. Antibiotics 24 : $727 \sim 731,1971$

3) Ohashi, Y.; S. Kawabe, K. Kono, Y. Ito \& T. Okuda: Chemistry of the antibiotic YA-56. I. Preliminary survey of acid hydrolysis and methanolysis products of YA-56. J. Antibiotics, in preparation.

4) Goodson, J. M. \& V. Distefano: Improvement of the chromatographic properties of Sephadex G-15. J. Chromatography $45: 139 \sim 142,1969$

5) IKekawa, T.; F. Imai, H. Hiranaka \& H. Umezawa: Separation of phleomycin components and their properties. J. Antibiotics $17: 194 \sim 199,1964$

6) Umezawa, H.; Y. Suhara, T. Takita \& K. Maeda : Purification of bleomycins. J. Antibiotics $19: 210 \sim 215,1966$

7) Argoudelis, A. D.; M. E. Bergy \& T. R. Pyke: Zorbamycin and related antibiotics. I. Production, isolation and characterization. J. Antibiotics $24: 543 \sim 556,1971$

8) The Upjohn Company: Zorbonomycin antibiotics active against fungi and bacteria. British Patent 1,277, 150, June 7, 1972 (U.S. appl. No. 865,096, Oct. 9, 1969)

9) Okuda, T. \& S. Awataguchr (Tanabe Seiyaku Co., Ltd.): Production of the new antibiotic YA-56. Japanese Patent '72-2557, Jan. 24, 1972 (Appl. No.73780, Sept. 17, 1969) 